\title{
Synthesis and Characterization of New Block Copolyurethanes Based on 1,2-Ethylene Bis(4-phenylisocyanate)
}

\author{
Tzong-Liu WANG ${ }^{\dagger}$ and Tar-Hwa HsiEH \\ Department of Chemical Engineering, National Kaohsiung Institute of Technology, \\ Kaohsiung, Taiwan 80782, Republic of China
}

(Received January 5, 1996)

\begin{abstract}
New block copolyurethanes consisting of 1,2-ethylene bis(4-phenylisocyanate), poly(ether glycol), and ethylenediamine were prepared. The major reactant diisocyanate was first synthesized using ethylene dianiline and phosgene as reagents and removing hydrogen chloride after the reaction. The diisocyanate was then reacted with poly(propylene glycol) (PPG) or poly(tetramethylene ether glycol) (PTMG) and chain extend with ethylene diamine to give the resultant segmented polyurethane elastomers. Both new polyurethanes were then characterized by Fourier transform infrared spectroscopy (FT-IR), Universal tensile tester, simultaneous DTA/TGA (SDT), and differential scanning calorimetry (DSC), etc., to determine the morphological structures, mechanical properties, and thermal stability of these polyurethanes. It was found that the PTMG based copolyurethane has superior mechanical properties and a good thermal stability due to its more cohesive hard domains and a better mutual stabilization effect between the hard and soft segments.

KEY WORDS Block Copolyurethanes / 1,2-Ethylene Bis(4-phenylisocyanate) / Ethylene Dianiline / Morphological Structures / Mechanical Properties / Thermal Stability / Hard Domains / Mutual Stabilization Effect /
\end{abstract}

Polyurethanes are a class of high performance materials for coatings, adhesives, elastomers, fibers, and foams. Based on a simple polyaddition reaction, materials with tailor-made properties can be produced from the broad variety of the chemical used. The versatile properties were attributed to a two-phase microstructure.

It has been indicated that the mechanical properties and thermal properties of the polyurethanes are determined not only by the chemical structure but also by the extent of the phase separation between the soft and the hard blocks. ${ }^{1-4}$ Moreover, it was also indicated that the presence of the additional methylene group in the phenylene-ethylene-phenylene (P2P) structure compared with the phenylene-methylene-phenylene (P1P) structure allows a planar stacking of the aromatic rings and interurethane hydrogen bondings which would be perpendicular to the aromatic rings. ${ }^{5}$ Hence, polyurethanes prepared from 1,2-ethylene bis(4-phenylisocyanate) (P2PDI) could be different in mechanical properties, light stability, hydrolytic resistance, and thermal stability with those prepared from the more commonly used diisocyanate, methylene bis(4-phenylisocyanate) (MDI). However, previous attempts directed toward the synthesis of P2PDI-based block copolyurethanes have yielded unsatisfactory low molecular weight products due to the reactivity of P2PDI being much higher than that of MDI. Consequently, the aim of this article was to report the improved synthetic step in yielding high molecular weight block copolyurethanes based on P2PDI. At first, block copolyrethanes formed from P2PDI with different polyols were synthesized. Both copolymers were then characterized to investigate their morphologies and properties.

\section{EXPERIMENTAL}

\section{Materials}

Ethyl acetate (EA, Tokyo Chemicals) was distilled over $\mathrm{P}_{2} \mathrm{O}_{5}$ before use. Phosgene (Fluka Chemicals) was dried by passing the gases through Drierite and $4 \AA$ molecular sieve before use. 4,4'-Ethylenedianiline (EDAN, Tokyo Chemicals) was purified by sublimation under vacuum. Ethylenediamine (EDA, Tokyo Chemicals), methyl isobutyl ketone (MIBK, Hayashi Chemicals), dimethylformamide (DMF, Tokyo Chemicals), dimethyl sufloxide (DMSO, Nacalai Tesque, Inc.), carbon tetrachloride (Union Chemicals), were distilled under reduced pressure. Poly(propylene glycol) (PPG, Wako Chemicals) and poly(tetramethylene ether glycol) (PTMG, Du Pont, Inc.) with molecular weight $(M W)=$ 1000 were degassed under vacuum at $55^{\circ} \mathrm{C}$ at $600 \mathrm{~Pa}$ $(4.5 \mathrm{mmHg})$ for 3 hours to remove any absorbed water.

\section{Synthesis of 1,2-Ethylene Bis(4-phenylisocyanate)}

In a flame-dried $1000 \mathrm{ml}$ three-necked round-bottomed flask equipped with a stirrer, a condenser fitted with a drying tube, and a thermometer, $200 \mathrm{ml}$ ethyl acetate (EA) was placed and filled with excess phosgene. The reaction was completed by adding dropwise, with slow stirring, a solution of $0.1 \mathrm{~mol}$ of $4,4^{\prime}$-ethylene dianiline in $500 \mathrm{ml}$ of ethyl acetate to a cooled $\left(-5 \sim 0^{\circ} \mathrm{C}\right)$ solution of $0.5 \mathrm{~mol}$ of phosgene in $200 \mathrm{ml}$ of ethyl acetate. A white precipitate formed. After the addition was complete, the reaction mixture was gently heated to reflux, giving a clear brownish solution. Excess solvent was then distilled, leaving brownish white crystals of the P2PDI. Recrystallization from carbon tetrachloride gave white crystals, melting at $92-93^{\circ} \mathrm{C}$.

\section{Preparation of Block Copolyurethanes}

The block copolyurethanes were synthesized by a prepolymer technique. PPG $(0.01 \mathrm{~mol})$ and $70 \mathrm{ml}$ of a

\footnotetext{
${ }^{\dagger}$ To whom correspondence should be addressed.
} 
$50 / 50$ mixture of dimethyl sulfoxide (DMSO) and methyl isobutyl ketone (MIBK) were placed in a dried, $250 \mathrm{ml}$ two-necked, round-bottomed flask equipped with a stirrer, a condenser fitted with a drying tube, and a thermometer. To this stirred solution was added $0.02 \mathrm{~mol}$ of P2PDI. The flask was shielded with aluminum foil and flushed with a slow stream of nitrogen during the addition. The reaction mixture was heated and stirred at $85^{\circ} \mathrm{C}$ for 3 hours in the dark. The reaction mixture was then cooled to room temperature and $0.01 \mathrm{~mol}$ of EDA in $15 \mathrm{ml}$ of DMSO was added to the rapidly stirred solution. After 30 minutes of stirring, the viscous solution was poured into water to isolate the polymer. The novel block copolyether-urethane-ureas was formed during this step. The block copolyurethane based on PTMG was prepared in a similar manner.

\section{Characterization}

Inherent viscosity $\left(\eta_{\text {inh }}\right)$ measurements were determined at a solution concentration of $0.5 \mathrm{~g}$ polymer per $100 \mathrm{ml}$ of solvent at $30^{\circ} \mathrm{C}$ using a Cannon-Fenske viscosimeter. Five flow times for each sample were taken and averaged.

Water absorption tests were carried out as follows. Film specimens were dried under vacuum at $60^{\circ} \mathrm{C}$ for 48 hours and were weighed with a microbalance. The specimens were then soaked in water at room temperature for 48 hours, blotted with paper towels and then quickly weighed. The absorbed water content of each specimen was evaluated from the weight difference before and after soaking in water.

The contact angle measurements were carried out with water using a contact angle goniometer (Rame-hart, Inc.). The urethane polymer films were solvent cast onto precleaned microscope slides and then vacuum dried for 24 hours before the contact angle measurements were taken. An average of five measurements were taken for each polymer examined.

Infrared spectra of the thin polymer films were obtained using a Bio-Rad FTS 165 Fourier transform infrared spectrometer. The spectra were obtained over the frequency range of 4000 to $400 \mathrm{~cm}^{-1}$ at a resolution of $4 \mathrm{~cm}^{-1}$.

Stress-strain data of urethane copolymers were obtained using an Universal Testing Machine (Shimadzu AGS-500A Series) with a $10 \mathrm{~kg}$ load cell and film grips. The crosshead speed was $50 \mathrm{~mm} \mathrm{~min}^{-1}$. Measurements were made at room temperature using $1.2 \mathrm{~cm} \times 0.4 \mathrm{~cm}$ dumbbell sample.

DSC thermograms from $-100 \sim 250^{\circ} \mathrm{C}$ were obtained using a Perkin-Elmer DSC 7 analyzer at a heating rate of $10^{\circ} \mathrm{C} \mathrm{min}{ }^{-1}$ under a dry helium purge.

Simultaneous differential thermal analysis (DTA) and thermogravimetric analysis (TGA) experiments (SDT) of the urethane copolymers were carried out on films placed in a platinum sample pan using a Du Pont SDT2960 analyzer. Sample films ranging from $3-4 \mathrm{mg}$ were cut into small pieces and loaded into the platinum pan and sealed in the sample chamber. The samples were heated from $50^{\circ} \mathrm{C}$ to $600^{\circ} \mathrm{C}$ under a nitrogen atmosphere at the rate of $10^{\circ} \mathrm{Cmin}^{-1}$. During the heating period, the weight loss and temperature difference as a function of temperature were recorded.

\section{RESULTS AND DISCUSSION}

Scheme 1 outlines the synthetic route of P2PDI and its copolymerization with different polyols. For convenience, they are designated as PPG-PU and PTMG$\mathrm{PU}$, respectively.

Although the prepolymer method was well-known in the synthesis of block copolyurethane, actual experimental work was rather difficult and many failures occurred. Since P2PDI had a very high reactivity, it was found that a purification step (recrystallization) before polymerization reaction was much important to ensure a stoichiometric ratio (i.e., $2 \mathrm{~mol}$ of P2PDI with $1 \mathrm{~mol}$ of polyol) has been reached. The presence of a strong absorption peak $c a$. at $2267 \mathrm{~cm}^{-1}$ is an indication of purity. In addition, preliminary experiments have shown that P2PDI reacted easily in the presence of light. Hence, the polymerization reactions must be carried out in the dark and under a nitrogen atmosphere. It was found that exposure of reaction mixtures to light results in an unsuccessful polymerization reaction. Moreover, the reaction temperature for the preparation of prepolymers must be raised rapidly to $85-90^{\circ} \mathrm{C}$ to avoid side reactions. The reactivity of $\mathrm{NCO}$ groups after prepolymer formation was conformed by the infrared spectra of both specimens as seen in Figure 1. As noted in our previous studies, ${ }^{6,7}$ block copolyurethanes of this type do not really consist of a simple $(\mathrm{AB})_{n}$ alternating structure, although they are customarily called alternating block copolyurethanes. They could contain significant amounts of dimeric soft and hard repeat segments. The structures of both copolyurethanes are also shown in Scheme 1. In a series of orienting experiments, it revealed that polyurethanes with the optimum physical properties (e.g., superior tensile properties, etc.) could be obtained in a mole ratio of $2 / 1 / 1$ of $\mathrm{P} 2 \mathrm{PDI} / \mathrm{polyol} /$ diamine.

The inherent viscosities, water contents, and water contact angles of the synthesized PPG and PTMG copolyurethanes are shown in Table I. Higher viscosity for the PTMG based polyurethane indicates that a higher moleculer weight was obtained. Higher water content and lower water contact angle of the PPG based polyurethane may suggest that the PPG-PU is more hydrophilic than that of the PTMG-based copolyurethane.

\section{Infrared Characterization}

The IR spectrum for PPG based copolyurethane is shown in Figure 2. This sample has a major NH band at $3313 \mathrm{~cm}^{-1}$ with a small peak at $3193 \mathrm{~cm}^{-1}$. Both peaks are hydrogen bonded. Additionally, the small shoulder at $3450-3480 \mathrm{~cm}^{-1}$ can be attributed to the free NH groups, while the extended shoulder to 3600 $\mathrm{cm}^{-1}$ may be assigned to $\mathrm{OH}$ groups of water absorbed. The PTMG based sample shows a similar trend, as can be seen in Figure 3. The major NH band appears at 3315 $\mathrm{cm}^{-1}$ with a small peak slightly shifted up to $3190 \mathrm{~cm}^{-1}$. Also, a negligble shoulder occurs at $3450 \mathrm{~cm}^{-1}$. It means more hydrogen bonding NH groups are present in the PTMG based sample.

In the case of the PPG based polyurethane, the carbon$\mathrm{yl}$ absorption in the urethane groups is at $1729 \mathrm{~cm}^{-1}$ 


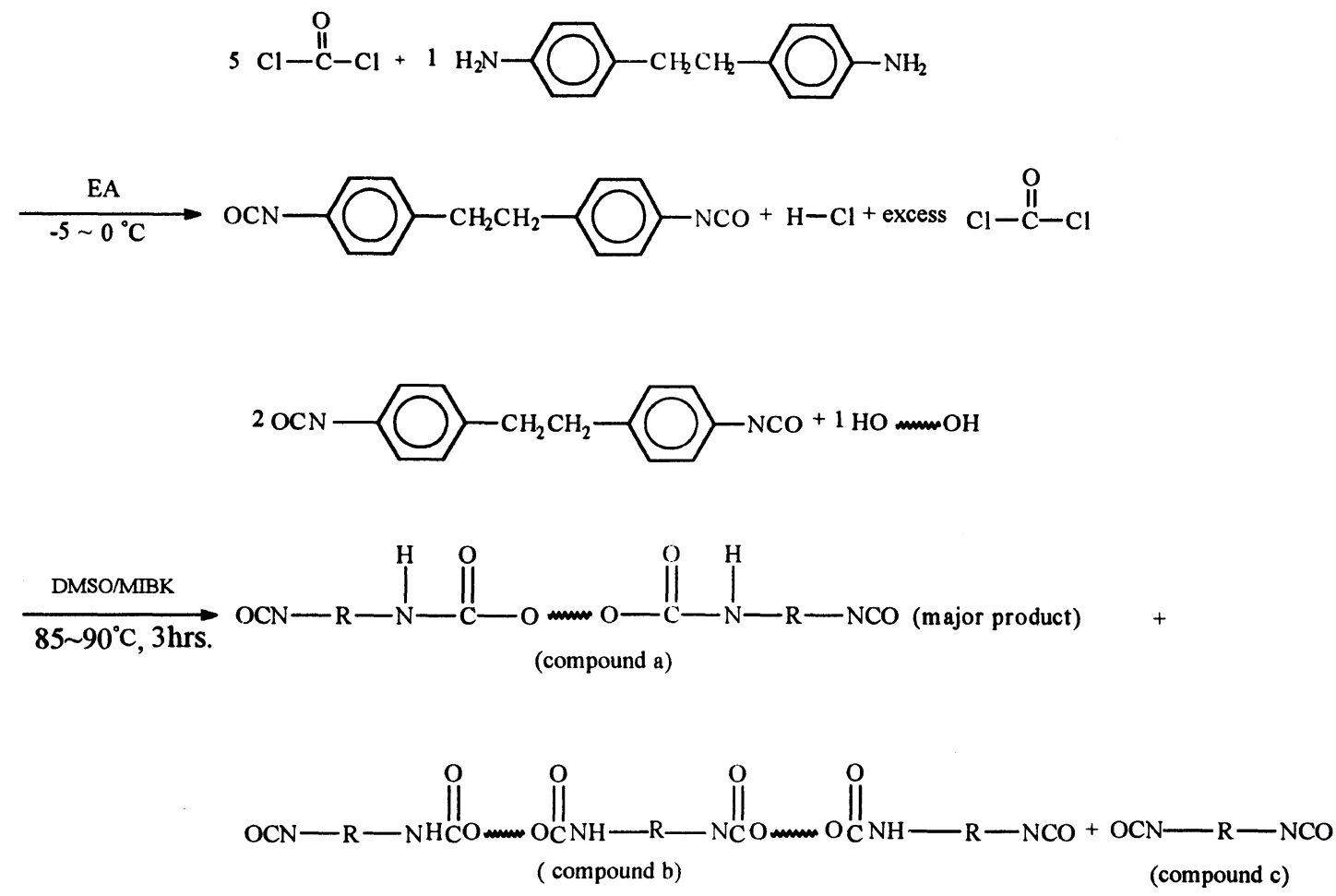

a, b and c compounds

a

b

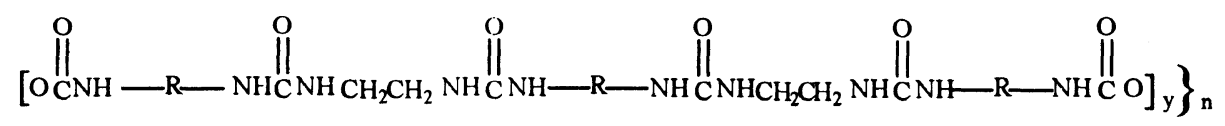

c

$(x+y=1)$

where

$$
\begin{aligned}
& \mathrm{R}=\bigcirc-\mathrm{CH}_{2} \mathrm{CH}_{2}-\bigcirc
\end{aligned}
$$

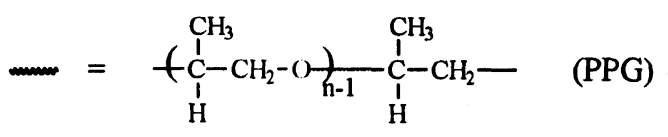

$$
\begin{aligned}
& \text { or } \quad\left(\mathrm{CH}_{2} \mathrm{CH}_{2} \mathrm{CH}_{2} \mathrm{CH}_{2} \mathrm{O}\right)_{\mathrm{n}-1} \mathrm{CH}_{2} \mathrm{CH}_{2} \mathrm{CH}_{2} \mathrm{CH}_{2}-\text { (PTMG) }
\end{aligned}
$$

Scheme 1. Synthetic route for preparation of P2P type copolyurethanes. 


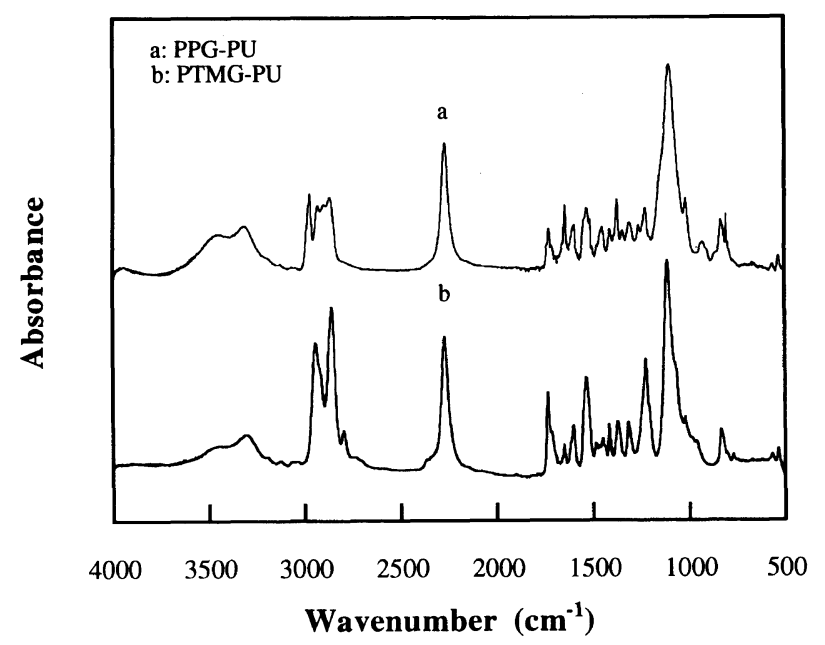

Figure 1. The infrared spectra of isocyanate-endcapped PPG and PTMG based prepolymers.

Table I. Water absorption and inherent viscosity of P2PDI based polyurethanes

\begin{tabular}{|c|c|c|c|}
\hline \multirow{2}{*}{ Sample } & Water absorption & Water contact angle & $\eta_{\mathrm{inh}}{ }^{\mathrm{a}}$ \\
\hline & $\%$ & degrees & $\mathrm{dlg}^{-1}$ \\
\hline PPG-PU & 4.86 & 64 & 0.44 \\
\hline PTMG-PU & 2.55 & 74 & 0.64 \\
\hline
\end{tabular}

${ }^{a}$ Inherent viscosity at $30^{\circ} \mathrm{C}$ in $\mathrm{N}, \mathrm{N}$-dimethylacetamide.

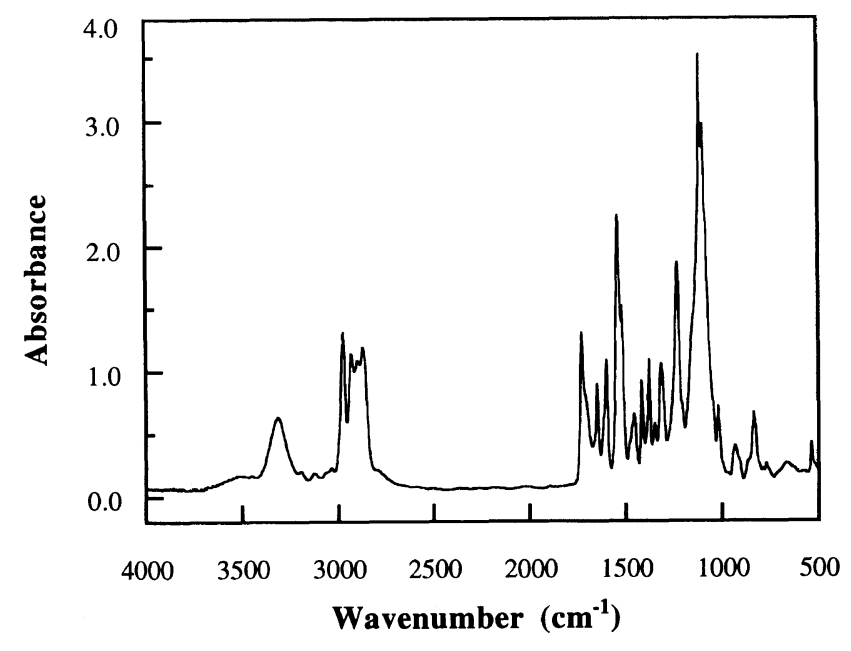

Figure 2. The infrared spectrum of PPG based polyurethane.

with a shoulder at $1706 \mathrm{~cm}^{-1}$. According to the infrared studies of Knutson and Lyman, ${ }^{8}$ these can be assigned to free and hydrogen bonded urethane carbonyl groups. For the PTMG based polyurethane, the urethane carbonyl absorptions split into two peaks at $1732 \mathrm{~cm}^{-1}$ and $1702 \mathrm{~cm}^{-1}$. However, the former absorption due to nonbonded $\mathrm{C}=\mathrm{O}$ stretching is dominant in the PPG based sample, whereas the latter bonded $\mathrm{C}=\mathrm{O}$ band is dominant in the PTMG based sample. This may suggest that the domain/matrix interface is quite sharp for the PTMG based sample and more phase mixing occurs in the PPG based material. For both samples, the urea carbonyl peaks appear at $c a .1650 \mathrm{~cm}^{-1}$ and correspond to hydrogen bonded urea carbonyls (which may be due to three-dimensional hydrogen bonding). After normali-

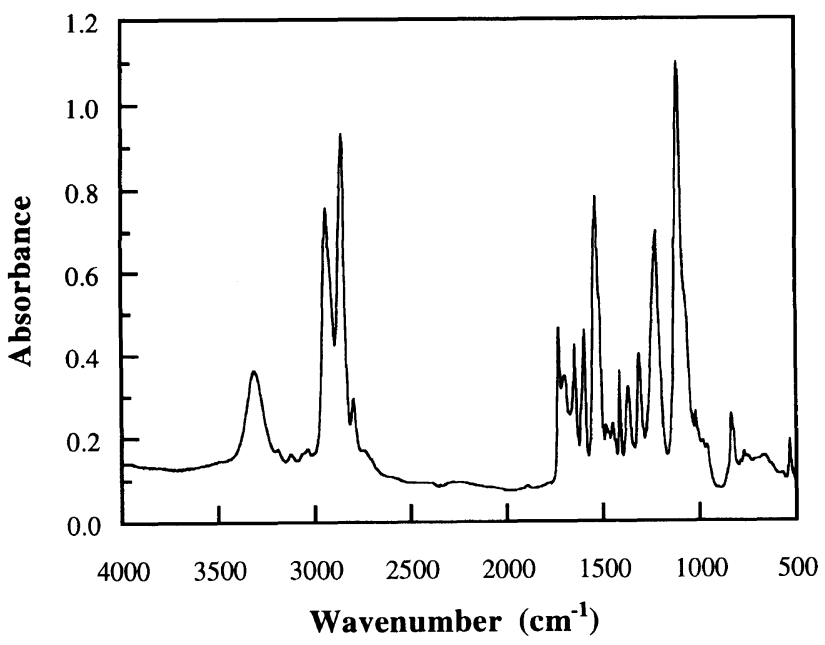

Figure 3. The infrared spectrum of PTMG based polyurethane.

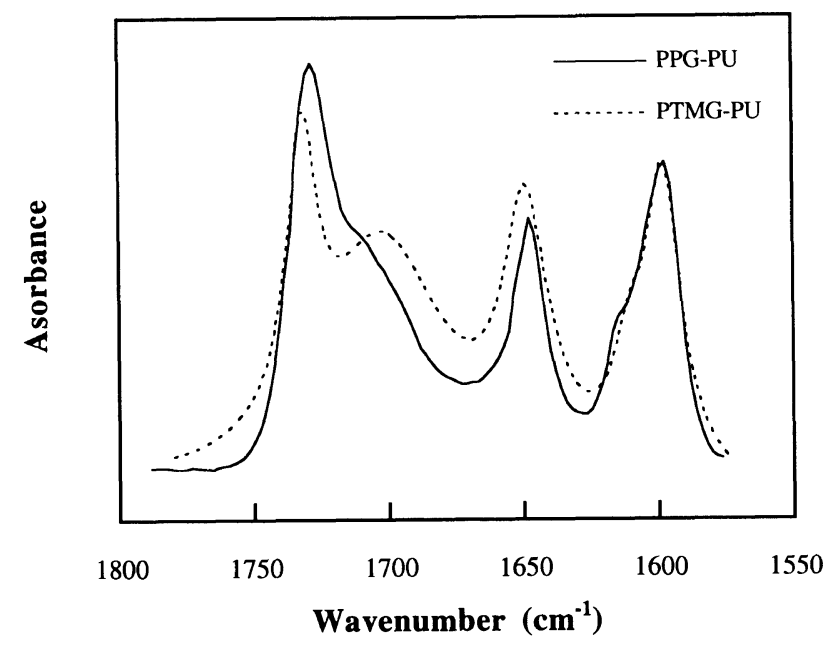

Figure 4. Expanded amide I absorption region of FT-IR spectra for PPG and PTMG based polyurethanes after normalization.

zation of the urea absorption by $\mathrm{C}=\mathrm{C}$ stretching of aromatic ring (Figure 4), it is apparently seen that more bonded urea carbonyl groups exist in the PTMG based sample due to its relative peak height being higher than that of the PPG based material. This indicates that there are more cohesive hard domains for the PTMG based polyurethane since interurea hydrogen bonding is dominant. The higher degree of hydrogen bonding in both urethane and urea absorption region suggests that the PTMG based sample has more perfect and more cohesive hard domains.

\section{Tensile Properties}

Stress-strain curves of the PPG and PTMG based-PUs are shown in Figure 5. As seen in the figure, the PTMG based material exhibits the high toughness and strength of typical segmented polyurethanes. It shows a higher Young's modulus and higher ultimate strength and elongation at break than does the PPG based sample. Higher initial modulus of PTMG-PU may be due to more cohesive hard domains resulting from interurethane and interurea hydrogen bondings. Since the PTMG based sample exhibits a higher tensile strength and larger elongation, it is apparent that more perfect and more cohesive hard domains are more efficient at stopping 


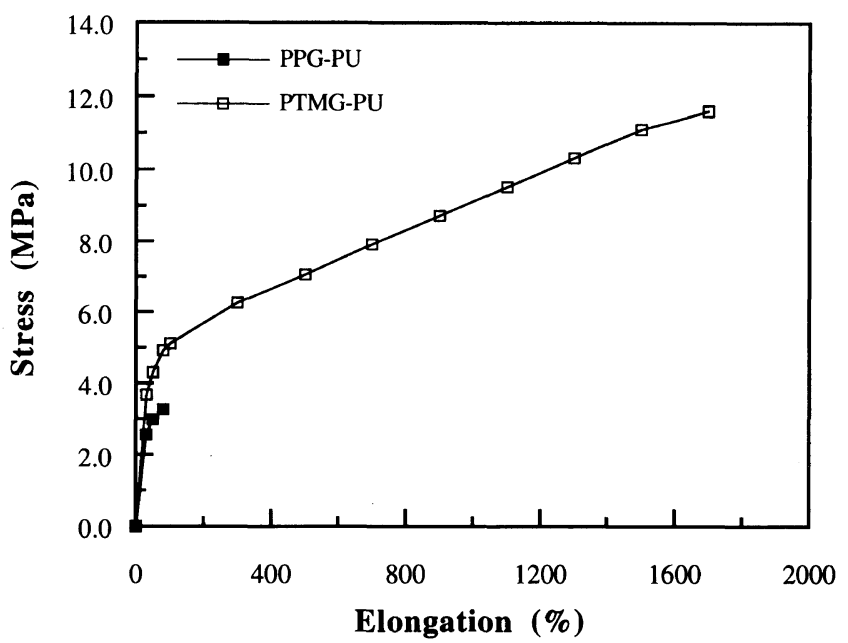

Figure 5. Stress-strain curves for PPG and PTMG based polyurethanes.

Table II. Tensile properties of the copolyurethanes

\begin{tabular}{|c|c|c|c|}
\hline \multirow{2}{*}{ Sample } & $\begin{array}{c}\text { Initial } \\
\text { modulus }\end{array}$ & $\begin{array}{l}\text { Ultimate } \\
\text { strength }\end{array}$ & \multirow{2}{*}{$\begin{array}{l}\text { Elongation } \\
\text { at break } / \%\end{array}$} \\
\hline & $\mathrm{MPa}$ & $\mathrm{MPa}$ & \\
\hline PPG-PU (MDI based) ${ }^{\mathrm{a}}$ & 12.28 & 21.57 & 887 \\
\hline PTMG-PU (MDI based) & 15.91 & 19.58 & 771 \\
\hline PPG-PU (P2PDI based) & 8.50 & 3.27 & 80 \\
\hline PTMG-PU (P2PDI based) & 12.27 & 11.61 & 1700 \\
\hline
\end{tabular}

a The data for MDI based copolyurethanes were based on same composition ratio and cited from ref 7 .

catastrophic crack growth than those for the PPG based sample, resulting in a larger tensile strength and elongation. As compared to MDI based polyurethanes, this type of polyurethanes are softer materials as shown in Table II.

\section{Differential Scanning Calorimetry}

DSC curves are shown in Figure 6 for the as-cast materials. Thermal transition data are summarized in Table III. Since pure PTMG and pure PPG had a glass transition temperature at $c a .-86^{\circ} \mathrm{C}$ and $-75^{\circ} \mathrm{C}^{9}$ respectively, it is apparent that there were still considerable phase mixings present in both samples from raising the $T_{\mathrm{g}}$ values of soft segments $\left(T_{\mathrm{gs}}\right)$. For both samples, the hard segment $T_{\mathrm{g}}\left(T_{\mathrm{gh}}\right)$ is about the same, indicating equal degree of phase separation in the hard domains may be present. In addition, lower hard segment $T_{\mathrm{gh}}$ values for both samples than that of MDI-PUs may suggest that this type of polyurethanes is softer than MDI based polyurethanes.

\section{Thermal Analysis}

SDT results of both samples are shown in Figure 7 . A smooth sinusoidal TGA curve was obtained for the PPG based polyurethane, suggesting a two step mechanism for its thermal degradation. Alternatively, the shoulder present in the TGA curve of the PTMG material may denote that three stages of degradation occur. From the TGA curves, it was found that degradation was comparatively slow in the solid polymers. The PPG and PTMG based samples show little weight loss up to

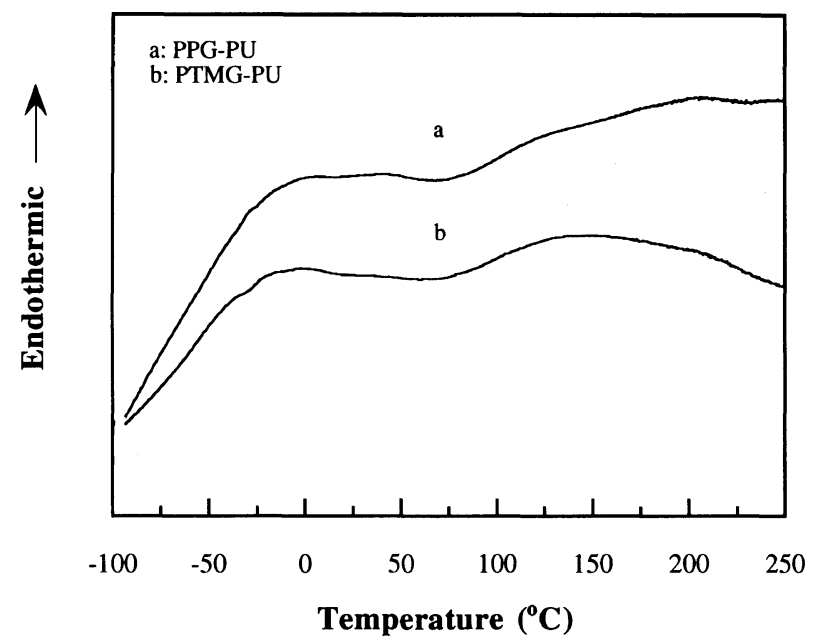

(a)

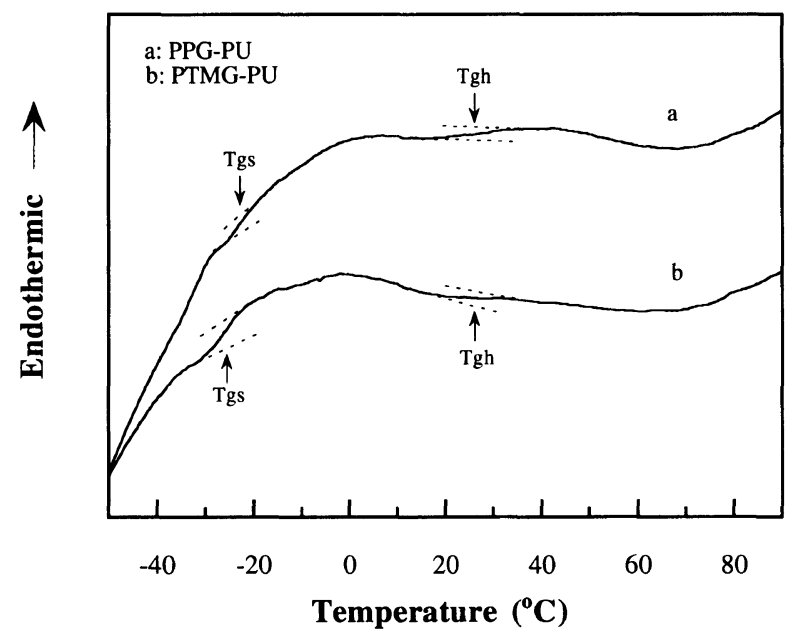

(b)

Figure 6. DSC curves of PPG and PTMG based polyurethanes: (a) full region $\left(-100 \sim 250^{\circ} \mathrm{C}\right)$; (b) expanded region $\left(-50 \sim 90^{\circ} \mathrm{C}\right)$.

Table III. DSC results of P2PDI based polyurethanes

\begin{tabular}{ccc}
\hline Sample & $T_{\mathrm{gs}} /{ }^{\circ} \mathrm{C}$ & $T_{\mathrm{gh}} /{ }^{\circ} \mathrm{C}$ \\
\hline PPG-PU & -22.2 & 26.1 \\
PTMG-PU & -26.3 & 26.5 \\
\hline
\end{tabular}

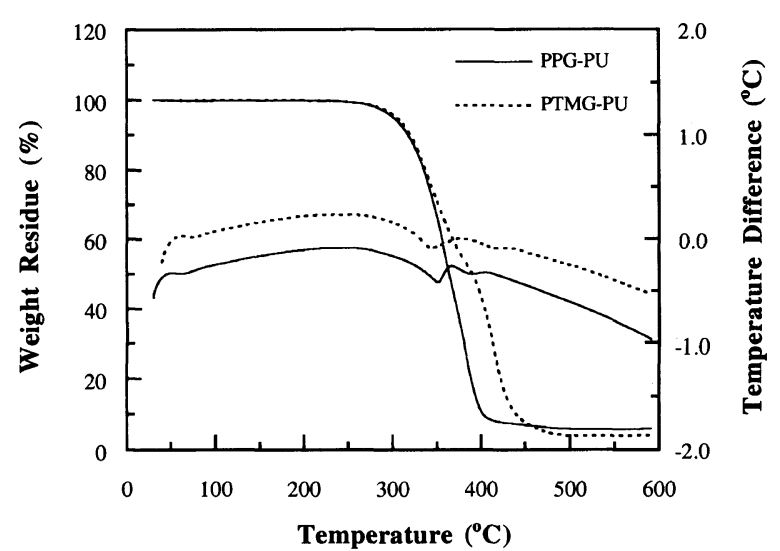

Figure 7. SDT curves of PPG and PTMG based polyurethanes under a nitrogen atmosphere. 
Table IV. SDT results of P2PDI based polyurethanes

\begin{tabular}{|c|c|c|c|c|c|c|}
\hline \multirow{2}{*}{ Sample } & \multirow{2}{*}{$\begin{array}{l}T_{\text {on }} /{ }^{\circ} \mathrm{C} \\
\text { (onset } \\
\text { temp.) }\end{array}$} & \multirow{2}{*}{$\begin{array}{c}T_{10 \%}{ }^{\circ} \mathrm{C} \\
(10 \% \\
\text { weight loss) }\end{array}$} & \multicolumn{2}{|c|}{$\begin{array}{c}\text { Weight } \\
\text { loss maximum }\end{array}$} & \multicolumn{2}{|c|}{$\begin{array}{l}\text { DTA peak/ } \\
{ }^{\circ} \mathrm{C}\end{array}$} \\
\hline & & & $T_{1 \mathrm{~m}} /{ }^{\circ} \mathrm{C}$ & $T_{2 \mathrm{~m}} /{ }^{\circ} \mathrm{C}$ & $T_{\mathrm{d} 1}$ & $T_{\mathrm{d} 2}$ \\
\hline PPG-PU & 297.3 & 317.2 & 357.5 & 380.3 & 350.0 & 390.5 \\
\hline PTMG-PU & 298.3 & 320.9 & 336.6 & 413.0 & 345.0 & 419.0 \\
\hline
\end{tabular}

about $250^{\circ} \mathrm{C}$, then degrade rapidly until about 400 and $450^{\circ} \mathrm{C}$, indicating that they are reasonably stable up to their threshold points of melting. In contrast, the PPG based polyurethane is less stable. Weight loss started at a lower temperature and was more rapid in PPG-PU. If the criteria for stability are taken as the temperature at which $10 \%$ weight loss occurred, the same conclusion can be reached. The variations of these temperatures with both samples are given in Table IV. Simultaneous DTA experiments demonstrated that the first degradation endotherm $\left(T_{\mathrm{d} 1}\right)$ was associated with the first weight loss maximum $\left(T_{1 \mathrm{~m}}\right)$ from the first derivative of the TGA curves, while the second degradation endotherm $\left(T_{\mathrm{d} 2}\right)$ could be attributed to the second weight loss maximum $\left(T_{2 \mathrm{~m}}\right)$. The DTA/TGA results fully support this interpretation. The TGA curve for the PTMG based sample shows that the apparent weight loss starts at a higher temperature. Hence, the PTMG based sample is more stable due to its higher decomposition temperature. Since it has been indicated that the initial degradation occurs in the hard segments, ${ }^{10}$ this may imply that the hard domains in the PPG based sample are less perfect.

\section{CONCLUSIONS}

Referring to the above results, it was found that the microphase separation, and the hydrogen-bonded domain structure that results from it, were the principal features that control the physical properties of both urethane copolymers. Infrared spectroscopy suggested that the PTMG based sample had a better phase separation, and had better mechanical properties than the PPG based polyurethane. This was confirmed by stress-strain measurements which showed that the PTMG based material had higher tensile strengths and ultimate extensibilities. Thermal analysis from TGA revealed that the more cohesive hard domains in the PTMG based sample enhanced the mutual stabilization effect between the hard and soft segments.

Acknowledgments. We gratefully acknowledge the support of this work by the National Science Council of Republic of China with Grant NSC 83-0117-C151-004 E.

\section{REFERENCES}

1. N. R. Legge, G. Holden, and H. E. Schroeder, "Thermoplastic Elastomers-A Comprehensive Review," Hanser Publishers, New York, N.Y., 1987, pp 13-46.

2. M. D. Lelah and S. L. Cooper, "Polyurethanes in Medicine," CRC Press, Inc., Boca Raton, Florida, 1986, pp 21-34.

3. T. A. Speckhard and S. L. Cooper, Rubber Chem. Technol., 59, 405 (1986).

4. K. C. Frisch, Rubber Chem. Technol., 45, 1442 (1972).

5. D. J. Lyman, J. Heller, and M. Barlow, Makromol. Chem., 84, 64 (1963).

6. T. L. Wang and D. J. Lyman, Polym. Bull., 27, 549-555 (1922).

7. T. L. Wang and D. J. Lyman, J. Polym. Sci., Part A, Polym. Chem, 31, 1983 (1993).

8. K. Knutson, Ph. D. Thesis, University of Utah, 1991.

9. Z. S. Petrovic and J. Ferguson, Prog. Polym. Sci., 16, 695 (1991).

10. J. Ferguson and Z. Petrovic, Eur. Polym. J., 12, 177 (1976). 